\title{
Patterns of impairment in decision-making capacity in Alzheimer's disease and its relationship with cognitive and clinical variables
}

\author{
Raquel Luiza Santos, ${ }^{1,2,3}$ iD José Pedro Simões Neto, ${ }^{4}$ (iD Tatiana Belfort, ${ }^{1}$ (iD Isabel Barbeito \\ Lacerda, ${ }^{1}$ (i) Marcia Cristina Nascimento Dourado ${ }^{1}$ (iD \\ ${ }^{1}$ Centro para Doenças de Alzheimer e Outros Transtornos Mentais na Velhice, Instituto de Psiquiatria, Universidade Federal do Rio de Janeiro, \\ Rio de Janeiro, RJ, Brazil. ${ }^{2}$ Departamento de Psicologia, Pontifícia Universidade Católica do Rio de Janeiro, Rio de Janeiro, RJ, Brazil. \\ ${ }^{3}$ Departamento de Psicologia, Universidade do Grande Rio, Duque de Caxias, RJ, Brazil. ${ }^{4}$ Departamento de Sociologia e Ciência Política, \\ Universidade Federal de Santa Catarina, Florianópolis, SC, Brazil.
}

\begin{abstract}
Objectives: To investigate the patterns of impairment in decision-making abilities and their relationship with cognitive and clinical symptoms in people with Alzheimer's disease. We hypothesized that decision-making abilities would not be impaired at the same level and would be related to impairment of global cognition and other clinical symptoms of the disease.

Methods: Using a cross-sectional design, we included a consecutive sample of 102 people with Alzheimer's disease and their respective caregivers. We investigated the relationship between decision-making capacity and quality of life (QoL), disease awareness, mood, functionality, neuropsychiatric symptoms, and cognition.

Results: Different levels of impairment were observed in the participants' decision-making abilities. Understanding, appreciation, and reasoning were correlated, but expressing a choice was only correlated with appreciation. Deficits in understanding were related to impaired disease awareness, lower self-reported QoL, and lower comprehension of spoken language. Better appreciation was related to better orientation and lower age. Better reasoning was related to better orientation and better self-reported QoL. Deficits in expressing a choice were related to lower self-reported QoL.

Conclusion: The pattern of impairment in decision-making abilities was not linear. Each decisionmaking ability was related to different cognitive and clinical deficits. Therefore, cognitive functioning is an insufficient criterion for judging an individual's decision-making ability.
\end{abstract}

Keywords: Alzheimer's disease; cognition; decision-making capacity; competence

\section{Introduction}

Decision-making capacity is a complex mental process involving four abilities ${ }^{1-5}: 1$ ) understanding is the ability to receive, store, and recall the meaning of information; 2) appreciation measures the ability to apply relevant information to one's situation or condition; 3 ) reasoning is the use of logical processes to compare response alternatives; 4) expression of choice is the ability to communicate a choice and consistently maintain it until implementation. Any interference in these abilities impairs decisionmaking capacity. ${ }^{5-7}$ These difficulties are worsened in cases of progressive cognitive impairment, such as in Alzheimer's disease (AD). ., $8-10^{-10}$

Several studies ${ }^{11-14}$ have suggested that people with $A D$ have globally impaired decision-making capacity, especially the moderate or severe stages of the disease

Correspondence: Marcia Cristina Nascimento Dourado, Avenida Nossa Senhora de Copacabana, 794/704, CEP 22050-001, Rio de Janeiro, RJ, Brazil.

E-mail: marciacndourado@gmail.com

Submitted Aug 11 2021, accepted Oct 16 2021, Epub Feb 282022. or when they are unaware of their diagnosis and prognosis. ${ }^{13,15,16}$ However, studies of people with mild $A D$ show that decision-making capacity tends to be partially preserved. ${ }^{17,18}$ For example, Hamann et al. ${ }^{18}$ suggested that although people with AD have deficits in decisionmaking capacity, they tend to wish for greater involvement and participation in decisions about their treatment, especially when their performance on cognitive screening tests is better.

Commonly, the cognitive domains that appear to predict decision-making capacity include episodic memory, confrontational naming, working memory, and executive function. ${ }^{19}$ Studies have shown the impact of episodic memory deficits, executive functioning, verbal memory, and phonemic fluency on the understanding domain. ${ }^{19,20}$ It has been reported that deficits in working memory, processing speed, and episodic memory are related to
How to cite this article: Santos RL, Simões Neto JP, Belfort $T$, Lacerda IB, Dourado MCN. Patterns of impairment in decisionmaking capacity in Alzheimer's disease and its relationship with cognitive and clinical variables. Braz J Psychiatry. 2022;44:271-278. http://dx.doi.org/10.1590/1516-4446-2021-2180 
impairment in the appreciation domain. ${ }^{17,20}$ In addition, changes in reasoning have been related to deficits in executive function, episodic memory, and expressive language. ${ }^{17,19}$ Conversely, few studies have investigated the relationship between decision-making capacity and the clinical variables of $A D$. In a previous study with a small sample, ${ }^{21}$ we found that understanding, appreciation, and reasoning were correlated with each other, but expressing a choice was not correlated with the other abilities. Additionally, decision-making abilities have been associated with cognitive impairment and other clinical deficits of $A D$, such as functional level or disease awareness. ${ }^{21}$ Therefore, we aimed to clarify patterns of impairment in decision-making abilities and their relationship with cognitive and clinical factors in people with AD. We hypothesized that decision-making abilities would not be impaired at the same level and that they would be related to impairment of global cognition and other clinical symptoms of the disease.

\section{Methods}

\section{Participants}

This cross-sectional study included a consecutive sample of 102 people with mild or moderate $A D$ who were treated at the outpatient unit of the Center for Alzheimer's Disease (Centro para Doença de Alzheimer e Outros Transtornos Mentais na Velhice), Institute of Psychiatry (Instituto de Psiquiatria), Universidade Federal do Rio de Janeiro (IPUB-UFRJ), as well as their respective caregivers. All participants had been diagnosed by their psychiatrist with possible or probable AD according to the DSM-IV. ${ }^{22}$ The diagnosis was determined through clinical interviews, screening tests for cognitive impairment, and laboratory and imaging tests. Only individuals with mild or moderate $A D$ according to the Clinical Dementia Rating (CDR) ${ }^{23}$ and with scores between 11-26 on the Mini-Mental State Examination (MMSE) ${ }^{24}$ were included in the study.

To avoid interference from other clinical conditions, we excluded people with a history of previous psychiatric conditions, aphasia, cranial traumatism, substance abuse, and epilepsy.

The person responsible for supervising and caring for the participant with $A D$ was considered the primary caregiver. We included only informal primary caregivers who had been previously informed about the care recipient's $A D$ diagnosis by the physician in charge.

\section{Instruments and procedures}

Trained psychologists and neuropsychologists performed the assessments. We collected the sociodemographic data from the participants' medical records and performed interviews with their caregivers. To ensure the anonymity of the responses and to prevent the participants and caregivers from discussing answers, both were interviewed separately. The participants with $A D$ completed assessments about decision-making capacity, quality of life (QoL), cognition, and disease awareness. The caregivers provided the following information about their patient: demographics, ability to perform activities of daily living (ADL), disease awareness, neuropsychiatric symptoms, mood, and dementia severity, and QoL.

\section{Instruments}

\section{Decision-making capacity}

The MacArthur Competence Assessment Tool for Treatment (MacCAT-T) ${ }^{21}$ is a semi-structured interview about the respondent's symptoms, diagnosis, treatment options, risk and benefits, and alternative treatments. The tool includes items assessing understanding, appreciation, reasoning, and expression of choice. The section on Understanding is subdivided into understanding - disorder, understanding - treatment, and understanding benefits/risks of treatment. This section also assesses whether the respondent can paraphrase information that was just provided. If the respondent lacks a clear understanding of the information, the interviewer may repeat this step. The Appreciation section assess whether respondents can apply information to their context (appreciation of the disorder) and whether they can recognize the possible benefits of treatment (appreciation of the treatment). The Reasoning section assesses whether respondents can determine any consequences of the treatment alternatives (consequential reasoning), compare the alternatives (comparative reasoning), and describe other consequences not previously offered by the interviewer (generating consequences). This section also assesses the logical consistency of their choice. In the Expression of choice section, respondents must establish a preference for one treatment option. The scores for each item are 2 (adequate), 1 (partially adequate), and 0 (inadequate). There is one quantitative score for each ability: 0-6 for Understanding, 0-4 for Appreciation, 0-8 for reasoning, and 0-2 for Expression of choice. The MacCAT-T has no total score or a cutoff score indicating whether respondents can competently make decisions about their treatment because the interviewer's judgment must consider all relevant information about the patient's global clinical status.

\section{Disease severity}

The stages of the full Clinical Dementia Rating protocol ${ }^{23}$ range from 0 (no dementia) to 3 (severe dementia), according to the degree of cognitive, behavioral, and ADL impairment.

\section{Global cognition}

The MMSE ${ }^{24}$ includes the assessment of temporal-spatial orientation, short delay memory, language, comprehension, and basic motor abilities. Scores range from 0 to 30 , with lower scores indicating more impaired cognition.

The Alzheimer's Disease Assessment Scale - Cognitive Subscale (ADAS-Cog) ${ }^{25}$ assesses the intensity of the cognitive impairment. The ADAS-Cog assesses word recall, naming objects and fingers, following commands, constructional praxis, ideational praxis, orientation, word recognition, remembering test instructions, spoken language ability, word finding difficulty, and comprehension 
of spoken language. The maximum score is 70 , with higher scores indicating cognitive impairment.

The Digit Span subtest of the Wechsler Adult Intelligence Scale ${ }^{26}$ includes direct order (DO) and inverse order (IO). The DO task assesses attention by having the respondent immediately repeat a numeric sequence spoken by the examiner. In the 10 task, which assesses cognitive flexibility, the respondent must repeat the given items in their inverse order. The maximum score is 30 points: 16 in the $\mathrm{DO}$ and 14 in the $\mathrm{IO}$.

\section{Functionality}

The Pfeffer Functional Activities Questionnaire ${ }^{27}$ includes 10 items on functional abilities. Each item is rated from normal (0) to dependent (3), and the maximum score is 30 points. Higher scores indicate greater functional impairment.

\section{Neuropsychiatric symptoms}

The Neuropsychiatric Inventory, ${ }^{28}$ which is taken by the caregiver, includes 12 items assessing the presence of delusions, hallucinations, dysphoria, anxiety, agitation/ aggressive behavior, euphoria, disinhibition, irritability/ emotional lability, apathy, aberrant motor activity, nocturnal behavior problems, and nutrition and appetite changes in the care recipient. The frequency of each symptom is reported on a scale from 1 (less frequent) to 4 (most frequent). The severity of each symptom is reported on a scale from 1 (mild) to 3 (intense). Total scores vary from 0 to 144 , with higher scores indicating greater neuropsychiatric symptoms.

\section{Mood}

The Cornell Scale for Depression in Dementia ${ }^{29}$ is used to evaluate physical signs, circadian cycle, and behavioral symptoms related to depression in people with dementia. Scores above 13 indicate the presence of depression.

\section{Disease awareness}

The Assessment Scale of Psychosocial Impact of the Diagnosis of Dementia, ${ }^{30}$ a 30 -item scale for caregivers of $A D$ patients, evaluates disease awareness in $A D$ by scoring conflicting responses across its domains, which include awareness of cognitive deficits and health conditions, awareness of emotional state, awareness of social functioning and relationships, and awareness of ADL. Total scores vary between 0 and 30 . Disease awareness may be preserved (scores 0-4), mildly impaired (scores 5-11), moderately impaired (scores 12-17), or absent (scores above 18).

\section{Quality of Life}

The Quality of Life in Alzheimer's Disease ${ }^{31}$ scale includes 13 dimensions (physical health, energy, mood, living situation, memory, family, marriage, friends, self as a whole, ability to do chores around the house, ability to do things for fun, money, and life as a whole). Total scores vary between 13 and 52 , with higher scores indicating better QoL. We considered both the patient's reported QoL and the caregiver's opinion of the patient's QoL.

\section{Statistical analysis}

We performed the statistical analysis in IBM SPSS version 22.0. The Kolmogorov-Smirnov and Levene tests were used to verify the normality of the distribution and the homoscedasticity of the data, respectively. Parametric variables were described as mean and standard deviation (SD), while non-parametric variables were described as median and range. The sociodemographic and clinical characteristics of the participants with $A D$ were analyzed using descriptive statistics. Matrices of Spearman's correlations were created to investigate the associations among the study variables (understanding, appreciation, reasoning, and expressing a choice) with the other cognitive and clinical variables. Correlations were interpreted as small $(0.10)$, medium $(0.30)$, or large $(0.50)$ in the magnitude of effect sizes. Based on the significant correlations identified between understanding, appreciation, reasoning, expressing a choice, and the other variables, multivariate linear regressions were performed to determine the factors related to decision-making abilities. To avoid type II error, we included only variables with strong correlations $(p \leqslant 0.01)$ in the linear regression models. Linear regression models were created to identify the strongest explanatory power among the fewest variables. Linear regressions were performed using the 'enter' method. The adjusted model was used to compare independent variables and explain the variation of dependent variables (understanding, appreciation, reasoning, and expressing a choice). The best models were selected according to a trade-off between the highest explained variance $\left(R^{2}\right)$ and the highest cross-validity (adjusted $\mathrm{R}^{2}$ ).

All significance tests were performed at a two-tailed level of $p \leqslant 0.05$.

\section{Ethics statement}

This study was approved by the IPUB-UFRJ ethics in research committee (CAAE 19656413.6.0000.5263). All patients and their caregivers provided written informed consent to participate.

\section{Results}

\section{Sociodemographic data}

We assessed 102 participants with mild $(n=68)$ or moderate $A D(n=34)$. The sample mainly consisted of women (64.7\%), whose mean age was 77.7 (7.1) years and who had 7.6 (3.9) years of education. Table 1 presents the sociodemographic data.

\section{Assessment of MacCAT-T domains}

The participants presented different levels of impairment in the abilities of decision-making: understanding (3.8, SD $1.2)$, reasoning (3.2, SD 1.6), appreciation (2.8, SD 1.1), 


\begin{tabular}{lc}
\hline Table 1 Participant sociodemographic data $(\mathrm{n}=102)$ \\
\hline Participants & $77.7(7.1)$ \\
$\quad$ Age & $5.2(3.5)$ \\
Disease duration & $7.6(3.9)$ \\
Education & $66(64.7)$ \\
Female, $\mathrm{n}(\%)$ & \\
Caregivers & \\
$\quad$ Age & $58.0(14.3)$ \\
Education & $12.2(3.1)$ \\
Female, $\mathrm{n}(\%)$ & $81.0(79.4)$ \\
\hline
\end{tabular}

Data presented as mean (standard deviation [SD]), unless otherwise specified.

and expressing a choice (1.8 SD, 0.5). The sample also showed moderate cognitive impairment according to the MMSE (19.2, SD 4.2), mild impairment in disease awareness (9.5, SD 5.3), moderate functional impairment (17.5, SD 8.2), and a mild level of neuropsychiatric symptoms (15.2, SD 12.6) and depressive symptoms (7.7, SD 5.5). The MacCAT-T data, the clinical variables, and the cognitive assessment of $A D$ participants are presented in Table 2.

\section{Univariate analysis}

Understanding, appreciation, and reasoning were positively correlated (understanding/appreciation $-\mathrm{r} 0.583$, $p \leqslant 0.001$; understanding/reasoning $-r$ 0.565, $p \leqslant$ 0.001 ; appreciation/reasoning $-r 0.370, p \leqslant 0.001$ ). Expressing a choice was only correlated with appreciation ( $r$ 0.253, $p \leqslant 0.01$ ).

The correlations between the decision-making domains and the cognitive variables showed that understanding was positively correlated with global cognition according to the MMSE $(r 0.264, p \leqslant 0.01)$ and cognitive flexibility ( $r$ 0.258, $p \leqslant 0.01$ ). Understanding was negatively correlated with the ADAS-Cog subitems orientation $(r-0.328, p \leqslant 0.001)$, spoken language ability $(r-0.300$, $p \leqslant 0.01)$, word finding difficulty $(r-0.332, p \leqslant 0.001)$, and comprehension of language $(r-0.340, p \leqslant 0.001)$. Therefore, inadequate understanding was related to lower global cognition. Appreciation was positively correlated with global cognition according to the MMSE ( $r$ 0.272, $p \leqslant 0.01)$ and negatively correlated with the ADAS-Cog subitems word recall $(r-0.279 ; p \leqslant 0.01)$, orientation $(r-0.363, p \leqslant 0.001)$, and word finding difficulty $(r-0.293 ; p \leqslant 0.01)$. Difficulties in appreciation were related to lower global cognition. Reasoning was only negatively correlated with the ADAS-COg subitem orientation $(r-0.290, p \leqslant 0.01)$. Expressing a choice was not correlated with cognition.

We also investigated the correlations between decision-making domains and clinical data. We observed that understanding was negatively correlated with lower disease severity $(r-0.336, p \leqslant 0.001)$, better functionality $(r-0.406, p \leqslant 0.001)$, preserved disease awareness $(r-0.498, p \leqslant 0.001)$, and was positively correlated with lower self-reported QoL ( $r 0.153, p \leqslant 0.001$ ). Appreciation was negatively correlated with lower disease severity $(r-0.254, p \leqslant 0.01)$, better functionality $(r-0.286$,
Table 2 MacCAT-T data and cognitive and clinical variables of participants with Alzheimer's disease $(n=102)$

\begin{tabular}{lc}
\hline MacCAT-T Understanding & $3.8(1.2)$ \\
MacCAT-T Appreciation & $2.8(1.1)$ \\
MacCAT-T Reasoning & $3.2(1.6)$ \\
MacCAT-T Expressing a Choice & $1.8(0.5)$ \\
MMSE & $19.2(4.2)$ \\
ADAS-Cog Total & $25.4(10.3)$ \\
ADAS-Cog Immediate word recall & $7.0(1.6)$ \\
ADAS-Cog Naming objects and fingers & $1.3(1.2)$ \\
ADAS-Cog Following commands & $0.6(0.9)$ \\
ADAS-Cog Constructional Praxis & $1.2(0.9)$ \\
ADAS-Cog Ideational Praxis & $1.1(1.3)$ \\
ADAS-Cog Orientation & $3.7(2.1)$ \\
ADAS-Cog Word recognition & $7.3(3.5)$ \\
ADAS-Cog Remembering test instructions & $1.0(1.4)$ \\
ADAS-Cog Spoken language ability & $0.5(0.9)$ \\
ADAS-Cog Word-finding difficulty in & $0.9(1.0)$ \\
spontaneous speech & \\
ADAS-Cog Comprehension of spoken & $0.7(0.9)$ \\
language & \\
Digit Span Test, direct order & $7.1(2.6)$ \\
Digit Span Test, inverse order & $3.0(1.7)$ \\
CDR 1, n (\%) & $68(66.7)$ \\
CDR 2, n (\%) & $34(33.3)$ \\
ASPIDD & $9.5(5.3)$ \\
NPI & $15.2(12.6)$ \\
CSDD & $7.7(5.5)$ \\
PFAQ & $17.5(8.2)$ \\
Self-report QoL-AD & $33.8(5.1)$ \\
QoL-AD Caregivers' Report & $29.8(5.9)$ \\
\hline
\end{tabular}

Data presented as mean (standard deviation [SD]), unless otherwise specified.

$A D=$ Alzheimer's disease; ADAS-Cog = Alzheimer's Disease Assessment Scale - Cognitive Subscale; ASPIDD = Assessment Scale of Psychosocial Impact of the Diagnosis of Dementia; CDR = Clinical Dementia Rating; CSDD = Cornell Scale for Depression in Dementia; MacCAT-T = MacArthur Competence Assessment Tool for Treatment; MMSE = Mini-Mental State Examination; NPI = Neuropsychiatric Inventory; PFAQ = Pfeffer Functional Activities Questionnaire; QoL-AD = Quality of life in Alzheimer's Disease.

$p \leqslant 0.01)$, and preserved disease awareness ( $r-0.337$, $p \leqslant 0.001)$. Reasoning was negatively correlated with preserved disease awareness $(r-0.283, p \leqslant 0.01)$ and lower self-reported QoL $(r-0.308, p \leqslant 0.01)$. Finally, expressing a choice was positively correlated with selfreported QoL ( $r 0.056, p \leqslant 0.0006)$. The data is available in Table 3.

\section{Multivariate analysis}

Four linear regression models were constructed for understanding, reasoning, appreciation, and expressing a choice. In each model, we included variables that were significantly correlated with each of the dependent variables.

Deficits in understanding were related to impaired disease awareness $(p \leqslant 0.001)$, lower self-reported QoL $(p \leqslant 0.05)$, and lower comprehension of spoken language in the ADAS-Cog $(p \leqslant 0.01)$. Better appreciation was related to better performance in the ADAS-Cog orientation subscale $(p \leqslant 0.001)$ and to lower participant age $(p \leqslant$ $0.001)$. Better reasoning was related to a better orientation score $(p \leqslant 0.01)$ and a higher self-reported QoL $(p \leqslant$ $0.01)$. Deficits in expressing a choice were only related to lower self-reported $Q o L(p \leqslant 0.01)$. The adjusted $R^{2}$ 
Table 3 Correlations between the four MacCAT-T domains and the cognitive and clinical variables

\begin{tabular}{|c|c|c|c|c|c|c|c|c|}
\hline \multirow{2}{*}{ Variables } & \multicolumn{2}{|c|}{ Understanding } & \multicolumn{2}{|c|}{ Appreciation } & \multicolumn{2}{|c|}{ Reasoning } & \multicolumn{2}{|c|}{ Expressing a choice } \\
\hline & $\mathrm{R}$ & $p$-value & $\mathrm{R}$ & $p$-value & $\mathrm{R}$ & $p$-value & $\mathrm{R}$ & $p$-value \\
\hline Understanding & & & 0.583 & $0.001 * *$ & 0.565 & $0.001 * *$ & 0.153 & 0.124 \\
\hline Appreciation & 0.583 & $0.001 * *$ & & & 0.370 & $0.001 * *$ & 0.253 & $0.01 *$ \\
\hline Reasoning & 0.565 & $0.001 * *$ & 0.370 & $0.001 * *$ & & & 0.165 & 0.098 \\
\hline Expressing a choice & 0.153 & 0.124 & 0.253 & $0.01 *$ & 0.165 & 0.098 & & \\
\hline Age & -0.161 & 0.106 & -0.296 & $0.003 *$ & -0.153 & 0.124 & -0.028 & 0.776 \\
\hline Disease duration & -0.158 & 0.113 & -0.081 & 0.419 & -0.135 & 0.177 & 0.01 & 0.918 \\
\hline Sex & 0.09 & 0.371 & 0.052 & 0.606 & 0.11 & 0.272 & 0.009 & 0.928 \\
\hline Education & 0.02 & 0.841 & 0.08 & 0.426 & 0.147 & 0.139 & 0.04 & 0.691 \\
\hline MMSE & 0.264 & $0.007 *$ & 0.272 & $0.006 *$ & 0.216 & 0.029 & 0.053 & 0.598 \\
\hline ADAS-Cog Immediate word recall & -0.216 & 0.029 & -0.279 & $0.005 *$ & -0.208 & 0.036 & -0.031 & 0.755 \\
\hline ADAS-Cog Naming objects and fingers & -0.117 & 0.242 & -0.232 & 0.019 & -0.055 & 0.582 & 0.057 & 0.567 \\
\hline ADAS-Cog Following commands & 0.004 & 0.967 & -0.153 & 0.125 & 0.056 & 0.573 & 0.058 & 0.560 \\
\hline ADAS-Cog Constructional praxis & -0.075 & 0.453 & -0.184 & 0.064 & -0.120 & 0.228 & -0.136 & 0.172 \\
\hline ADAS-Cog Ideational praxis & -0.094 & 0.349 & 0.074 & 0.461 & -0.242 & 0.014 & 0.009 & 0.926 \\
\hline ADAS-Cog Orientation & -0.328 & $0.001 * *$ & -0.363 & $0.001 * *$ & -0.290 & $0.003 *$ & -0.016 & 0.870 \\
\hline ADAS-Cog Word recognition & -0.181 & 0.069 & -0.153 & 0.126 & -0.194 & 0.050 & -0.032 & 0.751 \\
\hline ADAS-Cog Remembering test instructions & -0.234 & 0.018 & -0.171 & 0.085 & -0.135 & 0.176 & 0.035 & 0.723 \\
\hline ADAS-Cog Spoken language ability & -0.300 & $0.002 *$ & -0.227 & 0.022 & -0.211 & 0.030 & -0.139 & 0.164 \\
\hline ADAS-Cog Word-finding difficulty in spontaneous speech & -0.332 & $0.001 * *$ & -0.293 & $0.003 *$ & -0.154 & 0.121 & -0.071 & 0.476 \\
\hline ADAS-Cog Comprehension of spoken language & -0.340 & $0.001 * *$ & -0.188 & 0.058 & -0.190 & 0.056 & -0.144 & 0.148 \\
\hline Digit Span Test, direct order & 0.206 & 0.038 & 0.164 & 0.099 & 0.098 & 0.328 & -0.114 & 0.254 \\
\hline Digit Span Test, inverse order & 0.258 & $0.009 *$ & 0.128 & 0.201 & 0.110 & 0.270 & 0.017 & 0.867 \\
\hline CDR & -0.336 & $0.001 * *$ & -0.254 & $0.01 *$ & -0.229 & 0.021 & -0.031 & 0.758 \\
\hline ASPIDD & -0.498 & $0.001^{* *}$ & -0.337 & $0.001 * *$ & -0.283 & $0.004 *$ & -0.227 & 0.022 \\
\hline NPI & -0.116 & 0.246 & 0.023 & 0.821 & -0.045 & 0.656 & -0.105 & 0.295 \\
\hline CSDD & -0.016 & 0.872 & 0.050 & 0.620 & -0.011 & 0.910 & 0.011 & 0.911 \\
\hline PFAQ & -0.406 & 0.001 & -0.283 & $0.004 *$ & -0.249 & 0.012 & -0.197 & 0.047 \\
\hline Self-reported QoL-AD & -0.362 & 0.001 & -0.206 & 0.038 & -0.308 & $0.002^{*}$ & -0.270 & $0.006 *$ \\
\hline Caregiver reported QoL-AD & 0.153 & 0.125 & 0.080 & 0.425 & 0.133 & 0.182 & 0.056 & 0.575 \\
\hline
\end{tabular}

ADAS-Cog = Alzheimer's Disease Assessment Scale - Cognitive Subscale; ASPIDD = Assessment Scale of Psychosocial Impact of the Diagnosis of Dementia; CDR = Clinical Dementia Rating; CSDD = Cornell Scale for Depression in Dementia; MacCAT-T = MacArthur Competence Assessment Tool for Treatment; MMSE = Mini-Mental State Examination; NPI = Neuropsychiatric Inventory; PFAQ = Pfeffer Functional Activities Questionnaire; QoL-AD = Quality of life in Alzheimer's Disease.

$* p<0.01 ; * * p<0.001$.

Table 4 Regression models of factors related to the four MacCAT-T domains

\begin{tabular}{|c|c|c|c|c|c|}
\hline MacCAT-T domains & B & $\beta$ & $\mathrm{R}^{2}$ & Adjusted $\mathrm{R}^{2}$ & Significance \\
\hline \multicolumn{6}{|l|}{ Understanding } \\
\hline ASPIDD & -0.079 & -0.356 & 0.353 & 0.333 & 0.001 \\
\hline Self-reported QoL-AD & -0.050 & -0.212 & & & 0.015 \\
\hline Comprehension of spoken language & -0.346 & -0.261 & & & 0.003 \\
\hline \multicolumn{6}{|l|}{ Appreciation } \\
\hline Age & -0.046 & -0.308 & 0.231 & 0.215 & 0.001 \\
\hline Orientation & -0.203 & -0.403 & & & 0.001 \\
\hline \multicolumn{6}{|l|}{ Reasoning } \\
\hline Self-reported QoL-AD & -0.087 & -0.285 & 0.161 & 0.144 & 0.003 \\
\hline Orientation & -0.184 & -0.251 & & & 0.008 \\
\hline \multicolumn{6}{|l|}{ Expressing a choice } \\
\hline Self-reported QoL-AD & -0.025 & -0.264 & 0.070 & 0.061 & 0.007 \\
\hline
\end{tabular}

ASPIDD = Assessment Scale of Psychosocial Impact of the Diagnosis of Dementia; MacCAT-T = MacArthur Competence Assessment Tool for Treatment; QoL-AD: Quality of life - Alzheimer's disease patient.

values and the parameter estimates of the four regressions are shown in Table 4.

\section{Discussion}

Our study investigated patterns of impairment in decisionmaking abilities and their relationship with cognitive and clinical factors in people with AD. The different levels of impairment in decision-making abilities we observed indicate that the pattern of impairment is not linear and, most likely, primary impairment is attributable to understanding and reasoning deficits. Moreover, we found that each decision-making ability may be related to different cognitive and clinical deficits caused by the disease 
process. Thus, we can assume that cognitive functioning is an insufficient criterion for judging an individual's decision-making ability.

Our analysis demonstrated an association between deficits in understanding and impaired disease awareness, lower self-reported QoL, and lower comprehension of spoken language. Interestingly, this finding suggests that people with preserved disease awareness tend to have better understanding of the reasoning behind their decisions. Our sample mainly consisted of $A D$ patients with mildly impaired awareness; studies report that people who are aware of the disease tend to be partially or fully competent to make decisions about their treatment. ${ }^{20,32}$ Nevertheless, few studies have investigated the relationship between awareness and decision-making capacity to consent to treatment. ${ }^{15,32,33}$ This finding indicates the importance of including an awareness assessment when evaluating decision-making capacity in dementia.

We also found that better understanding was related to better comprehension of spoken language in the ADASCog. This result is in line with the finding that understanding is the ability that most depends on global cognitive functioning, specifically language and cognitive flexibility. ${ }^{34,35}$ Stormoen et al. ${ }^{14}$ observed that language function is the most important predictor of decision-making capacity. Decision-making assessment involves tasks based on an oral and written presentation of information and the interaction between the AD patient and the health professional. During the tasks, the patient should apprehend, codify, and evoke the benefits and risks of accepting treatment and should verbally indicate a choice. ${ }^{14}$

Furthermore, difficulties in understanding have been associated with lower self-reported QoL. This might be due to preserved comprehension of the characteristics and prognosis of the disease. Clinically, this point highlights the need to balance support and empowerment, as well as to balance increasing awareness and the potential to cause harm. Kiriaev et al. ${ }^{36}$ recently suggested that since people with dementia often have a diminished capacity to express their preferences, healthcare decisions are usually made by family caregivers and physicians, who underestimate the patient's autonomy and decisions, which could reduce the quality of their life decisions.

We found that difficulties in appreciation were related to deficits in the ADAS-Cog orientation subitem and older age. Time and spatial orientation tended to contribute to appreciating and reasoning about pieces of information or orientation. Moreover, it could be more challenging for older people to appreciate and develop a rational process about alternatives. Thus, people with orientation difficulties tend to misjudge the applicability of information regarding their $\mathrm{ADL}$. In addition, the association between appreciation and age might be related to decreased stimuli. Usually, people with AD have fewer requirements and are less intellectually active, which would hinder their orientation and more objective judgment. ${ }^{21}$ This important finding supports the benefits of cognitive stimulation for people with AD.

Deficits in reasoning and expression of choice were also related to lower self-reported QoL. This relationship shows that $A D$ is more than just a cognition disorder, since people with $A D$ are involved in different social environments, and their decisions exist in a context. ${ }^{37} \mathrm{QoL}$ in dementia involves cognitive functioning, ADL, social interaction, and psychological well-being. ${ }^{31}$ Recently, a systematic review ${ }^{38}$ summarized the stated preferences of people with dementia, finding that the essential patientrelated outcomes were QoL and self-efficacy, which indicates the relationship between reasoning and QoL. Another possible explanation for the relationship between reasoning, expression of choice, and self-reported QoL could be the indirect role of disease awareness in this relationship. A previous study ${ }^{39}$ by our group found a bidirectional association between lower mood and functionality levels, impaired disease awareness, and decreased functionality, as well as that all these variables were associated with self-reported QoL. Further studies using a path analysis model could better clarify the relationship between reasoning, expression of choice, and self-reported QoL.

It would be helpful to add a comment here about expression of choice. Although understanding, appreciation, and reasoning were correlated, expression of choice was only correlated with appreciation. This finding aligns with Moye et al., ${ }^{11}$ suggesting that appreciation may be less commonly impaired in individuals with dementia. Thus, although most of the patients in this study might choose a treatment, their expression of this choice was not always supported by adequate understanding and reasoning. Clinically, our data is fundamental for health professionals and family members, since they must help increase the autonomy of dementia patients through a supervised decision-making process. ${ }^{40}$ Another point related to expression of choice is the assessment instrument. In general, understanding has more robust measures than the other components. ${ }^{19}$ For example, in the MacCAT-T, expression of choice is assessed with one item, whereas there are 13 items related to understanding. Such differences could affect the correlations between decision-making abilities.

Our study has some limitations. The fact that our sample was drawn from an outpatient unit may prevent generalization of the results. We also could have included a control group of cognitively healthy individuals to compare the decision-making capacity to consent to treatment. Furthermore, our findings may not be considered actual predictors of decision-making capacity, but rather predictors of decision-making capacity according to MacCAT-T results.

Our data suggest that there is a correlation between the different abilities involved in decision-making capacity to consent to treatment. However, although people with AD may express a choice, they may not be cognitively able to express a logical decision about their treatment. Nevertheless, these patients usually want to participate in decision-making about their treatment and have greater participation, especially in mild AD. Although understanding, appreciation, and reasoning are related to cognitive functioning, our findings also highlight the role and impact of clinical aspects, such as disease awareness, in decision-making capacity. Additionally, the observed relationship between decision-making abilities and QoL 
indicates ethical and clinical challenges for caregivers and physicians. Caregivers and health professionals should not exclude AD patients from the decision process, since this may decrease their subjective sense of QoL. We suggest assisted proxy decision-making as a way to include the patient and avoiding risky, possibly inappropriate decisions. We also suggest a capacity-building approach that can include recourse to a living will and advance care directives, as well as to personal values or belief systems. Our data can contribute to the development of assisted decision-making protocols and interventions that to help individuals understand their disease and treatment.

\section{Acknowledgements}

MCND is a level 2 researcher funded by the Conselho Nacional de Desenvolvimento Científico e Tecnológico (CNPq) and the Fundação de Amparo à Pesquisa do Estado do Rio de Janeiro (FAPERJ).

\section{Disclosure}

The authors report no conflicts of interest.

\section{References}

1 Gleichgerrcht E, Ibáñez A, Roca M, Torralva T, Manes F. Decisionmaking cognition in neurodegenerative diseases. Nat Rev Neurol. 2010;6:611-23.

2 de Siqueira AS, Yokomizo JE, Jacob-Filho W, Yassuda MS, Aprahamian I. Review of decision-making in game tasks in elderly participants with Alzheimer disease and mild cognitive impairment. Dement Geriatr Cogn Disord. 2017;43:81-8.

3 Appelbaum PS, Grisso T. Assessing patients' capacity to consent to treatment. N Engl J Med. 1988;319:1635-8.

4 Appelbaum PS. Clinical practice. Assessment of patients' competence to consent to treatment. N Engl J Med. 2007;357:1834-40.

5 Appelbaum PS. Consent in impaired populations. Curr Neurol Neurosci Rep. 2010;10:367-73.

$6 \mathrm{Kim}$ SY, Karlawish JH, Caine ED. Current state of research on decision-making competence of cognitively impaired elderly persons. Am J Geriatr Psychiatry. 2002;10:151-65.

7 Moberg PJ, Rick JH. Decision-making capacity and competency in the elderly: a clinical and neuropsychological perspective. NeuroRehabilitation. 2008;23:403-13.

8 Brand M, Schiebener J. Interactions of age and cognitive functions in predicting decision-making under risky conditions over the life span. J Clin Exp Neuropsychol. 2013;35:9-23.

9 Pertl MT, Benke T, Zamarian L, Delazer M. Effects of healthy aging and mild cognitive impairment on a real-life decision-making task. J Alzheimers Dis. 2017;58:1077-87.

10 Zamarian L, Weiss EM, Delazer M. The impact of mild cognitive impairment on decision making in two gambling tasks. J Gerontol B Psychol Sci Soc Sci. 2011;66:23-31.

11 Moye J, Karel MJ, Gurrera RJ, Azar AR. Neuropsychological predictors of decision-making capacity over 9 months in mild-to-moderate dementia. J Gen Intern Med. 2006;21:78-83.

12 Lui VW, Lam LC, Luk DN, Wong LH, Tam CW, Chiu HF, et al. Capacity to make treatment decisions in chinese older persons with very mild dementia and lild Alzheimer disease. Am J Geriatr Psychiatry. 2009;17:428-36.

13 Maxmin K, Cooper C, Potter L, Livingston G. Mental capacity to consent to treatment and admission decisions in older adult psychiatric inpatients. Int J Geriatr Psychiatry. 2009;24:1367-75.

14 Stormoen S, Almkvist O, Eriksdotter M, Sundström E, Tallberg IM. Cognitive predictors of medical decision-making capacity in mild cognitive impairment and Alzheimer's disease. Int $\mathrm{J}$ Geriatr Psychiatry. 2014;29:1304-11.
15 Karlawish JH, Casarett DJ, James BD, Xie SX, Kim SY. The ability of persons with Alzheimer disease (AD) to make a decision about taking an AD treatment. Neurology. 2005;64:1514-9.

16 Huthwaite JS, Martin RC, Griffith HR, Anderson B, Harrell LE, Marson DC. Declining medical decision-making capacity in mild $A D$ : a two-year longitudinal study. Behav Sci Law. 2006;24:453-63.

17 Okonkwo O, Griffith HR, Belue K, Lanza S, Zamrini EY, Harrell LE, et al. Medical decision-making capacity in patients with mild cognitive impairment. Neurology. 2007;69:1528-35.

18 Hamann J, Bronner K, Margull J, Mendel R, Diehl-Schmid J, Bühner $\mathrm{M}$, et al. Patient participation in medical and social decisions in Alzheimer's disease. J Am Geriatr Soc. 2011;59:2045-52.

19 Palmer BW, Harmell AL. Assessment of healthcare decision-making capacity. Arch Clin Neuropsychol. 2016;31:530-40.

20 Okonkwo OC, Griffith HR, Belue K, Lanza S, Zamrini EY, Harrell LE, et al. Cognitive models of medical decision-making capacity in patients with mild cognitive impairment. J Int Neuropsychol Soc. 2008;14:297-308.

21 Santos RL, Sousa MF, Simões JP Neto, Bertrand E, Mograbi DC, Landeira-Fernandez $\mathrm{J}$, et al. MacArthur competence assessment tool for treatment in Alzheimer disease: cross-cultural adaptation. Arq Neuropsiquiatr. 2017;75:36-43.

22 American Psychiatric Association. Diagnostic and Statistical Manual of Mental Disorders, Fourth Edition, Text Revision (DSM-IV-TR). Arlington: American Psychiatric Publishing; 2000.

23 Maia AL, Godinho C, Ferreira ED, Almeida V, Schuh A, Kaye J, et al. [Application of the Brazilian version of the CDR scale in samples of dementia patients]. Arq Neuropsiquiatr. 2006;64:485-9.

24 Bertolucci PH, Brucki SM, Campacci SR, Juliano Y. [The Mini-Mental State Examination in a general population: impact of educational status]. Arq Neuropsiquiatr. 1994;52:1-7.

25 Schultz RR, Siviero MO, Bertolucci PH. The cognitive subscale of the "Alzheimer's Disease Assessment Scale" in a Brazilian sample. Braz J Med Biol Res. 2001;34:1295-302.

26 Nascimento E. Adaptação, validação e normatização de uma amostra brasileira. In: Wechsler D, editor. WAIS-III: Escala de Inteligência Wechsler para Adultos - manual para administração e avaliação. São Paulo: Casa do Psicólogo; 2004. p. 161-92.

27 Dutra MC, Ribeiro RS, Pinheiro SB, de Melo GE, Carvalho GA. Accuracy and reliability of the Pfeffer Questionnaire for the Brazilian elderly population. Dement Neuropsychol. 2015;9:176-83.

28 Camozzato AL, Kochhann R, Simeoni C, Konrath CA, Pedro Franz A, Carvalho A, et al. Reliability of the Brazilian Portuguese version of the Neuropsychiatric Inventory (NPI) for Alzheimer s disease patients and their caregivers. Int Psychogeriatr. 2008;20:383-93.

29 Portugal Mda G, Coutinho ES, Almeida C, Barca ML, Knapskog AB, Engedal K, et al. Validation of Montgomery-Åsberg Rating Scale and Cornell Scale for depression in dementia in Brazilian elderly patients. Int Psychogeriatr. 2012;24:1291-8.

30 Dourado MC, Mograbi DC, Santos RL, Sousa MF, Nogueira ML, Belfort T, et al. Awareness of disease in dementia: factor structure of the assessment scale of psychosocial impact of the diagnosis of dementia. J Alzheimers Dis. 2014;41:947-56.

31 Novelli MM, Nitrini R, Caramelli P. Validation of the Brazilian version of the quality of life scale for patients with Alzheimer disease and their Caregivers. Aging Ment Health. 2010;14:624-31.

32 Gambina G, Bonazzi A, Valbusa V, Condoleo MT, Bortolami O, Broggio $E$, et al. Awareness of cognitive deficits and clinical competence in mild to moderate Alzheimer's disease: their relevance in clinical practice. Neurol Sci. 2014;35:385-90.

33 Consentino S, Metcalfe J, Cary MS, De Leon J, Karlawish J. Memory awareness influences everyday decision-making capacity about medication management in Alzheimer's disease. Int J Alzheimers Dis. 2011;2011:483897.

34 Gurrera RJ, Moye J, Karel MJ, Azar AR, Armesto JC. Cognitive performance predicts treatment decisional abilities in mild to moderate dementia. Neurology. 2006;66:1367-72.

35 Gurrera RJ, Karel MJ, Azar AR, Moye J. Agreement between instruments for rating treatment decisional capacity. Am J Geriatr Psychiatry. 2007;15:168-73.

36 Kiriaev O, Chacko E, Jurgens JD, Ramages M, Malpas P, Cheung G. Should capacity assessments be performed routinely prior to discussing advance care planning with older people? Int Psychogeriatr. 2018;30:1243-50. 
37 Viaña JN, Mclnerney F, Brodaty H. Beyond cognition: psychological and social transformations in people living with dementia and relevance for decision-making capacity and opportunity. Am J Bioeth. 2020;20:101-4.

38 Lepper S, Rädke A, Wehrmann H, Michalowsky B, Hoffmann W. Preferences of cognitively impaired patients and patients living with dementia: a systematic review of quantitative patient preference studies. J Alzheimers Dis. 2020;77:885-901.
39 Dourado MCN, Santos RL, Fischer A, Mograbi DC. Modeling quality of life in Alzheimer disease: the impact of cognitive, functional, and mood variables in self and carers' perceptions. J Geriatr Psychiatry Neurol. 2021;34:668-67.

40 Smebye KL, Kirkevold M, Engedal K. How do persons with dementia participate in decision making related to health and daily care? A multi-case study. BMC Health Serv Res. 2012; 12:241. 